\title{
1st Biennial Congress of the Eurasian Colorectal Technologies Association (ECTA), 13-15 November 2009, Guangzhou, China
}

\author{
Felix Aigner
}

Published online: 9 February 2010

(C) Springer-Verlag 2010

The first congress of the 2007 founded ECTA took place in Guangzhou, China, chiefly organized by the local team under Prof. J.P. Wang from the Guangdong Provincial Hospital of Gastrointestinal \& Anal Diseases. In the framework of this congress the first official Governing Council with several founding members was constituted and confirmed Prof. F. Seow-Choen as President. The major goals or philosophies of this association are to focus on the East-West cooperations between Asia and Europe in terms of exchange programs on an educational as well as scientific level as Prof. J. Pfeifer mentioned in his introduction talk. Still there are profound differences in colorectal cancer incidence between East and West and therapeutical strategies somehow differ due to the influence for example by traditional Chinese Medicine which was clearly illustrated by Chinese speakers during the sessions. Secondly, ECTA offers companies to present new technologies for diagnosis and treatment of colorectal diseases which are seriously and objectively reviewed by members of the Scientific Committee of the association from an academic point of view. Both goals should improve the character of the society in spreading our knowledge of colorectal surgery to developing areas of the world where health care often fails due to poverty and, thus, make ECTA different from other colorectal associations worldwide.

Regardless of the cold and rainy weather in Guangzhou during the conference, the shiny character of the scientific and well-organized social program convinced the attendees of supporting ECTA's philosophies. The next challenge will be to forward these goals to colorectal surgeons in Europe and Asia and bring in many young, interested and motivated colleagues to join ECTA. Scientific conferences and educational grants would not exist without the financial support from the medical industry and that is why ECTA wants to give the companies an opportunity to present new technologies during the biennial congresses and establish randomized-controlled trials to prove their efficacy and efficiency apart from traditional surgical techniques.

Again, I want to address my appreciation to the organizing committee of Prof. Wang fort his outstanding conference, and I am really looking forward to the next ECTA congress in Torino, Italy, organized by Prof. M. Morino in 2011.

\footnotetext{
F. Aigner $(\bowtie)$

Chairman of the Section for Young Surgeons,

Eurasian Colorectal Technologies Association, Department of Visceral, Transplant and Thoracic Surgery, Innsbruck Medical University, Innsbruck, Austria

e-mail: felix.aigner@i-med.ac.at
} 